\title{
Preterm Birth and Associated Factors among Mothers Who Gave Birth in Gondar Town Health Institutions
}

\author{
Kahsay Gebreslasie \\ Department of Midwifery, College of Medicine and Health Science, University of Gondar, 196 Gondar, Ethiopia \\ Correspondence should be addressed to Kahsay Gebreslasie; kahsay.zenebe@gmail.com
}

Received 16 February 2016; Revised 14 March 2016; Accepted 14 April 2016

Academic Editor: Ann M. Mitchell

Copyright (C) 2016 Kahsay Gebreslasie. This is an open access article distributed under the Creative Commons Attribution License, which permits unrestricted use, distribution, and reproduction in any medium, provided the original work is properly cited.

Background. The birth of a preterm infant has a greater risk of developmental disabilities, health, and growth problems than infants born at full term. The main aim of this study was to assess the prevalence and associated factors of preterm birth Northwest Ethiopia, Gondar town health institutions. Methods. Facility based cross section study was undertaken. Systematic sampling was used to select 540 study participants. Both bivariate and multiple logistic regression were fitted. Variables with $p$ value $<0.05$ and $95 \%$ $\mathrm{CI}$ in multivariate were considered statistically significant. Result. This study showed that $4.4 \%$ from the total 540 mothers gave a preterm birth. The covariates of pregnancy induced hypertension (AOR 5.36 (95\% CI 1.8, 15.96)) and being HIV positive (AOR $3.4(95 \%$ CI $1.25,9.2)$ ) were found to be significantly associated with preterm birth. Conclusion. The main factors for preterm birth were pregnancy induced hypertension and being HIV positive. Therefore, still efforts have to be made to decrease the prevalence of preterm birth and for timely management of pregnancy induced hypertension and identifying pregnant women at the risk of preterm delivery like HIV positive women and proving quality of healthcare may decrease the rate of preterm birth and its consequences.

\section{Background}

According to the World health organization (WHO) preterm birth is birth of the baby before 37 completed weeks of gestational age [1]. The Global Action Report on Preterm Birth provides the first-ever national, regional, and global estimates of preterm birth. The report shows that preterm birth is on the rise in most countries and is now the second leading cause of death globally for children under five, after pneumonia [2]. The born too soon report, published in 2012, drew global attention to the issue of preterm birth and reported that more than 1 in 10 of the world's babies are born too soon each year, 15 million each year [3-5].

The preterm infant causes significant health consequences to the infant and economic costs for families and communities. Advances in prenatal and neonatal care have improved the survival for preterm infants but those infants who do survive have a greater risk of developmental disabilities, health, and growth problems than infants born at full term [6]. About $75 \%$ of perinatal deaths and $50 \%$ of neurological abnormalities are directly related to preterm $[7,8]$.
The majority of preterm birth remains vulnerable to long term complications that may persist all over their lives. The main resulting morbidities are neurosensory deficits (blindness, deafness), intraventricular hemorrhage, necrotizing enter colitis, and delay in physical and mental development $[9,10]$. According to the report from "white paper on preterm birth" in 2009, of all 4 million annual early neonatal deaths (deaths within the first 7 days of life) that are not related to congenital malformations, $28 \%$ are due to preterm birth [11].

The major risk factor of preterm delivery was absence or inadequate prenatal care, low monthly income, no contraceptive use, cesarean delivery, and clinical complications during pregnancy $[12,13]$.

Worldwide, 13 million babies are born preterm annually. Rates are generally the highest in low and middle income countries, and increasing in some middle and high income countries [14].

The highest rates occurred in Africa and North America, where $11.9 \%$ and $10.6 \%$, respectively, of the births were preterm. Europe, where $6.2 \%$ of the births were preterm, had the lowest rate [15]. According to a meta-analysis reported 
by Philip Steer the overall estimates of preterm birth rates range from $5 \%$ in developed countries to $25 \%$ in developing countries [16].

According to Ethiopian profile of preterm and low birth weight prevention and care, in Ethiopia, 320,000 babies are born too soon each year and 24,000 children under five die due to direct preterm complications [17].

The result of this study may help program managers, Woreda Health office, stake holders, and obstetric care providers to design appropriate interventions to reduce preterm birth and decrease newborn morbidity and mortality. It may ultimately help to reduce child mortality rate; also it will help to fill the research gaps in the study area and as base line information for other areas of the country.

\section{Methods}

Facility based cross-sectional study was conducted among mothers who gave birth in Gondar town health institutions. The study was conducted in Gondar town which is located in Amhara Regional State, Northwest Ethiopia. Gondar is located $745 \mathrm{~km}$ away from Addis Ababa, the capital of Ethiopia. Gondar town has a total population of 248784 (117673 male and 131111 female). Females in reproductive age groups (15-49 years) are 58863. There are 6 governmental and 3 private health institutions which provide services related to delivery [18]. The study was conducted from March to May, 2012.

The study populations were mothers who gave birth during the study period at Gondar town health institution but mothers who gave birth to two or more babies were excluded from the study because this term for multiple pregnancy is varied depending on the number of fetus in the uterus. Systematic sampling was employed to select study participants from each health institution. Average numbers of clients who delivered daily during data collection period were estimated. To estimate the total number of delivery within a data collection time client registration book/record for a month prior to data collection were reviewed and every third delivered mothers were involved in the study.

Using single population proportion formula the final sample size was found to be 540 .

The outcome measure of interest was preterm birth. The independent variables included sociodemographic characteristics (age, sex of the baby, marital status, educational status, residence, religion, ethnicity, occupational status, and monthly income) and obstetrics related variables (parity, number of antenatal visit, hemoglobin, maternal HIV status, urinary tract infection during pregnancy, malaria attack during pregnancy, and pregnancy induced hypertension).

Data was collected by face to face interviews using a structured and pretested questionnaire and gestational age was determined by last normal menstrual period and by early ultrasound which means ultrasound done in the first trimester because ultrasound done in the first trimester is more reliable as to plus or minus one week but mothers who did not know last menstrual period and have no early ultrasound were excluded from the study.
Both data collectors and supervisors were trained on how to collect the data. The data was entered, cleaned, and edited using EPI INFO version 2002 and exported to SPSS version 16.0 software packages for analysis. Both bivariate and multiple logistic regression were fitted. Variables with $p$ value $<0.2$ in bivariate analysis were entered into multivariate analysis and variables with $p$ value $<0.05,95 \% \mathrm{CI}$ in multivariate were considered statistically significant.

Ethical clearance was obtained from Institutional Review Board (IRB) of University of Gondar. Formal letter of cooperation was written for Gondar Woreda Health Department and each health institution. After the data collectors were informed about the purpose of the research, verbal and written consent was obtained from each study participant.

\section{Results}

3.1. Sociodemographic Characteristics. A total of 540 mothers from Gondar town health institutions were included in the study, making a response rate of $100 \% .357$ (66.1\%) out of the total respondents were urban residents. The mean age of the respondents was 25 years. Eighty-one point three percent of respondents were between ages 20-35 years old. With regard to sex of newborn more than half were male. Regarding marital status of the mothers, most 500 (92.6\%) were married. Near to two-thirds of the mothers were housewives (Table 1).

3.2. Maternal and Obstetric Characteristics. Three hundred and forty-eight $(64.4 \%)$ have four and above antenatal care visits during their pregnancy. Out of 540 mothers 275 (50.9\%) were primigravida. Regardless of anemia of the mothers onefifth were screened and out of them 17 (15.17\%) were anemic. Out of 540 women all were tested for HIV infection and 50 (9.3\%) were positive for the infection. Out of the 540 mothers 27 (5\%) have urinary tract infection (Table 2).

3.3. Characteristics of Infants. Out of the 540 newborns 24 $(4.4 \%)$ were delivered at less than 37 weeks of gestation. Mean birth weight of the infants was $2.9 \mathrm{~kg}$ (range 1.5 to 4.3 ). The mean gestational age of the newborns was 39.49 weeks with minimum 31 and maximum 44 weeks. The prevalence of low birth weight was found to be $17.4 \%$.

3.4. Factors Associated with Preterm Birth. The covariates of pregnancy induced hypertension and being HIV positive status were found to be significantly associated with preterm birth in multiple logistic regression analysis.

Those women with pregnancy induced hypertension were 5 times $(\mathrm{AOR}=5.36,95 \% \mathrm{CI}=1.8,15.96)$ more likely to deliver preterm than those women without pregnancy induced hypertension. HIV positive status women were significantly associated with preterm birth; being HIV positive status has threefold risks for preterm birth $(\mathrm{AOR}=3.4,95 \% \mathrm{CI} 1.25,9.2)$. (Table 3).

\section{Discussion}

In this study the prevalence of preterm birth was found to be $4.4 \%$. This finding is lower than the prevalence of preterm 
TABLE 1: Sociodemographic characteristics of respondents, Gondar, Northwest Ethiopia, 2012.

\begin{tabular}{|c|c|c|}
\hline Variable & Frequency & Percent \\
\hline \multicolumn{3}{|l|}{ Residence } \\
\hline Urban & 357 & 66.1 \\
\hline Rural & 183 & 33.9 \\
\hline \multicolumn{3}{|l|}{ Age } \\
\hline$\leq 19$ & 64 & 11.9 \\
\hline $20-34$ & 441 & 81.6 \\
\hline$\geq 35$ & 35 & 6.5 \\
\hline \multicolumn{3}{|l|}{ Religion } \\
\hline Orthodox & 474 & 87.7 \\
\hline Muslim & 61 & 11.3 \\
\hline Others & 5 & 1 \\
\hline \multicolumn{3}{|l|}{ Educational status } \\
\hline Unable to read and write & 145 & 26.8 \\
\hline Read and write & 13 & 2.4 \\
\hline Primary education & 103 & 19.1 \\
\hline Secondary education and college & 279 & 51.7 \\
\hline \multicolumn{3}{|l|}{ Marital status } \\
\hline Married & 500 & 92.6 \\
\hline Divorced/separated & 39 & 7.2 \\
\hline Widowed & 1 & 0.2 \\
\hline \multicolumn{3}{|l|}{ Ethnicity } \\
\hline Amhara & 525 & 97.2 \\
\hline Tigre & 13 & 2.4 \\
\hline Oromo & 2 & 0.4 \\
\hline \multicolumn{3}{|l|}{ Occupational status } \\
\hline Housewife & 337 & 62.4 \\
\hline Government employer & 79 & 14.7 \\
\hline Private employee & 44 & 8.1 \\
\hline Daily laborer & 70 & 13 \\
\hline Farmer & 10 & 1.9 \\
\hline
\end{tabular}

birth in Ethiopia, 10.1\%, which was reported by the Global Action Report on Preterm Birth in 2010 [19].

The finding on this study was also lower than a crosssectional study conducted in Addis Ababa and Debre Marqos referral hospital, which reported the prevalence rate of $7.1 \%$ and $11.6 \%$, respectively [20,21]. This might be due to the difference in study areas and also it might be due to the time of study; currently in the study area it might be better health seeking behaviour among the study participants.

This finding is almost in line with study conducted in developed countries. For instance, the 2010 WHO bulletin on cross-sectional analyses of prospective surveys reported that preterm birth rates have been reported to range from $5 \%$ to $7 \%$ of births [15]. It might be shown that our country Ethiopia brings change in health status of the mother and newborn.

The preterm birth in our study was found to be lower than the study conducted in Nigeria on 2010 prevalence rate was $19.9 \%$ [18]. This higher prevalence of preterm birth in
TABLE 2: Obstetrics and maternal condition of the respondents in Gondar health institution, Northwest Ethiopia, March-May, 2012.

\begin{tabular}{lcc}
\hline Variable & Frequency & Percent \\
\hline Parity & 275 & \\
$\quad$ Primigravida & 265 & 50.9 \\
$\quad$ Multipara & & 49.1 \\
Number of antenatal visits & 192 & \\
$\quad<4$ & 348 & 35.6 \\
$\geq 4$ & & 64.4 \\
Hemoglobin done & 112 & \\
$\quad$ Yes & 428 & 20.7 \\
$\quad$ No & & 79.3 \\
Hemoglobin & 17 & 15.17 \\
$\quad<11$ & 95 & 84.82 \\
$\quad \geq 11$ & & \\
HIV status & 50 & 9.3 \\
Positive & 490 & 90.7 \\
Negative & & 55 \\
Urinary tract infection & 25 & \\
Yes & 513 & \\
No & &
\end{tabular}

Nigeria might be due to included multiple pregnancies in the research, multiple pregnant mothers has over distended uterus and can cause preterm birth.

Other cross-sectional studies in Brazil showed a prevalence of $21.7 \%$, which is higher than this study [3-5]. A study also done in USA had reported higher rates of preterm birth, $12.5 \%$ in 2004 and $12.8 \%$ in 2006 [22, 23]. This might be in USA; there is high prevalence of chronic diseases that may predispose to preterm birth.

This study revealed that a significant association was found between pregnancy induced hypertension and preterm birth. Mothers who had pregnancy induced hypertension had five times increased risk of having a preterm birth than those mothers without pregnancy induced hypertension [AOR = $5.36,95 \% \mathrm{CI}=1.8-15.96)$. This finding is in line with crosssectional studies conducted in Brazil and Bangladesh in 2011, Addis Ababa, Ethiopia, in 2007, and another cross-sectional study in Nigeria $[10,11,13,17]$, respectively. The reason for this might be due to the fact that complications of pregnancy induced hypertension can cause vascular damage to placenta. This induces the oxytocin receptors, which results in preterm labor and delivery.

Being HIV positive mothers is another factor found to be significantly associated with preterm birth which means that HIV positive mothers were three times delivering their baby at preterm as compared with mothers free from HIV. This finding is in line with a study done in Zahedan, Islamic Republic of Iran, where mothers with infection during pregnancy were more likely to deliver preterm birth baby than without infection [19]. This might be due to the drug effect and immunity of the mother risk factor for preterm birth. 
TABLE 3: Bivariate and multiple logistic regression of selected variables in relation to preterm birth among $(n=540)$ newborn delivered in Gondar town health institution 2012.

\begin{tabular}{|c|c|c|c|c|}
\hline \multirow{2}{*}{ Variable } & \multicolumn{2}{|c|}{ Preterm birth } & \multirow{2}{*}{ COR $(95 \% \mathrm{CI})$} & \multirow{2}{*}{$\operatorname{AOR}(95 \% \mathrm{CI})$} \\
\hline & Yes & No & & \\
\hline \multicolumn{5}{|c|}{ Monthly income } \\
\hline$<1963 \mathrm{~EB}$ & 16 & 263 & $1.9(0.8,4.57)$ & \\
\hline$>1964 \mathrm{~EB}$ & 8 & 253 & & \\
\hline \multicolumn{5}{|c|}{ Pregnancy induced hypertension } \\
\hline Yes & 5 & 23 & $5.6(1.95,16.44)$ & $5.36(1.8,15.96)$ \\
\hline No & 19 & 493 & & \\
\hline \multicolumn{5}{|l|}{ Malaria } \\
\hline Yes & 4 & 35 & $2.74(0.89,8.48)$ & \\
\hline No & 20 & 481 & & \\
\hline \multicolumn{5}{|c|}{ Number antenatal care } \\
\hline$<4$ & 13 & 179 & $2.2(0.97,5)$ & \\
\hline$\geq 4$ & 11 & 337 & & \\
\hline \multicolumn{5}{|l|}{ HIV status } \\
\hline Positive & 6 & 44 & $3.57(1.35,9.47)$ & $3.4(1.25,9.2)$ \\
\hline Negative & 18 & 472 & & \\
\hline
\end{tabular}

\section{Conclusion}

The main factors for preterm birth were pregnancy induced hypertension and being HIV positive. Therefore, still efforts have to be made to decrease the prevalence of preterm birth and for timely management of pregnancy induced hypertension; specially controlling of hypertension is very important to maintain blood flow to the fetus and identifying pregnant women at risk of preterm delivery like HIV positive women and proving quality of healthcare may decrease the rate of preterm birth and its consequences.

\section{Competing Interests}

The author declares that they have no competing interests.

\section{Authors' Contributions}

Kahsay Gebreslasie wrote the proposal, participated in data collection, analyzed the data, and drafted the paper. The author read and approved the final paper.

\section{Acknowledgments}

The author is very grateful to the University of Gondar for the approval of the ethical clearance and for their technical and financial support of this study. Then, the author would like to thank all data collectors and all the respondents.

\section{References}

[1] I. Balchin, J. C. Whittaker, P. J. Steer, and R. F. Lamont, "Are reported preterm birth rates reliable? An analysis of interhospital differences in the calculation of the weeks of gestation at delivery and preterm birth rate," British Journal of Obstetrics and Gynaecology, vol. 111, no. 2, pp. 160-163, 2004.

[2] The Born too soon report, http://www.who.int/pmnch/media/ news/2012/preterm_birth_report/en/.

[3] J. Belizan, P. Buekens, C. P. Howson, M. V. Kinney, and J. E. Lawn, "Born too soon," Reproductive Health, vol. 10, supplement $1,2013$.

[4] H. Blencowe, S. Cousens, M. Z. Oestergaard et al., "National, regional, and worldwide estimates of preterm birth rates in the year 2010 with time trends since 1990 for selected countries: a systematic analysis and implications," The Lancet, vol. 379, no. 9832, pp. 2162-2172, 2012.

[5] S. Oza, J. E. Lawn, D. R. Hogan, C. Mathers, and S. N. Cousens, "Neonatal cause-of-death estimates for the early and late neonatal periods for 194 countries: 2000-2013," Bulletin of the World Health Organization, vol. 93, no. 1, pp. 19-28, 2015.

[6] Institute of Medicine (US) Committee on Understanding Premature Birth and Assuring Healthy Outcomes, Preterm Birth: Causes, Consequences, and Prevention, R. E. Behrman and A. S. Butler, Eds., National Academies Press, 2007.

[7] N. Marlow, D. Wolke, M. A. Bracewell, and M. Samara, "Neurologic and developmental disability at six years of age after extremely preterm birth," The New England Journal of Medicine, vol. 352, no. 1, pp. 9-19, 2005.

[8] J. A. Martin, B. E. Hamilton, P. D. Sutton et al., "Births: final data for 2005," National Vital Statistics Reports, vol. 56, no. 6, pp. 1-3, 2007.

[9] M. H. B. Carvalho, R. E. Bittar, P. P. A. Maganha, S. V. Pereira, and M. Zugaib, "Association between bacterial vaginoses and spontaneous preterm birth," Revista Brasileira de Ginecologia e Obstetrícia, vol. 23, no. 529, p. 33, 2001.

[10] L. F. Cram, M. I. Zapata, E. C. Toy, and B. Baker III, "Genitourinary infections and their association with preterm labor," American Family Physician, vol. 65, no. 2, pp. 241-248, 2002.

[11] The Global and Regional Toll, March of Dimes White Paper on Preterm Birth, March of Dimes Foundationc, 2009. 
[12] C. C. Guerra, M. C. de Moraes Barros, A. L. Goulart, L. V. Fernandes, B. I. Kopelman, and A. M. dos Santos, "Premature infants with birth weights of 1500-1999 g exhibit considerable delays in several developmental areas," Acta Paediatrica, vol. 103, no. 1, pp. el-e6, 2014.

[13] A. C. de Almeida, A. C. P. de Jesus, P. F. T. Lima, M. F. M. de Araújo, and T. M. de Araújo, "Maternal risk factors for premature births in a public maternity hospital in ImperatrizMA," Revista Gaúcha de Enfermagem, vol. 33, no. 2, pp. 86-94, 2012.

[14] M. G. Gravett, C. E. Rubens, and T. M. Nunes, "Global report on preterm birth and stillbirth (2 of 7): discovery science," BMC Pregnancy and Childbirth, vol. 10, supplement 1, article S2, 2010.

[15] S. Beck, D. Wojdyla, L. Say et al., "The worldwide incidence of preterm birth: a systematic review of maternal mortality and morbidity," Bulletin of the World Health Organization, vol. 88, no. 1, pp. 31-38, 2010.

[16] P. Steer, "The epidemiology of preterm labour," BJOG: An International Journal of Obstetrics and Gynaecology, vol. 112, supplement 1, pp. 1-3, 2005.

[17] Ethiopia profile of preterm and low birth weight prevention and care, http://www.everypreemie.org/wp-content/uploads/2015/ 11/Ethiopia.pdf.

[18] B. O. Olusanya and G. E. Ofovwe, "Predictors of preterm births and low birthweight in an inner-city hospital in sub-Saharan Africa," Maternal and Child Health Journal, vol. 14, no. 6, pp. 978-986, 2010.

[19] H. B. Sc, M. Z. Oestergaard, D. Chou et al., "Lawn. Data from national, regional and worldwide estimates of preterm birth rate," The Global Action Report on Preterm Birth, vol. 4, p. 2010, 2010.

[20] M. Koblinsky, F. Tain, and S. Tesfaye, "Reducing maternal mortality and increasing use of skilled birth attendance: Ethiopia and MDG 5," Ethiopian Journal of Reproductive Health, vol. 4, no. 1, pp. 4-15, 2010.

[21] T. Bekele, A. Amanon, and K. Z. Gebreslasie, "Preterm birth and associated factors among mothers who gave birth in Debremarkos Town Health Institutions, 2013 institutional based cross sectional study," Gynecology \& Obstetrics, vol. 5, no. 5, article 292, pp. 1-5, 2015.

[22] C. Holzman, R. Kelly, P. Senagore et al., "Placental vascular pathology findings and pathways to preterm delivery," American Journal of Epidemiology, vol. 170, no. 2, pp. 148-158, 2009.

[23] March of Dimes Foundation Data Book for Policy Makers, Maternal, Infant, and Child Health in the United States, March of Dimes Foundation Data Book for Policy Makers, 2010. 


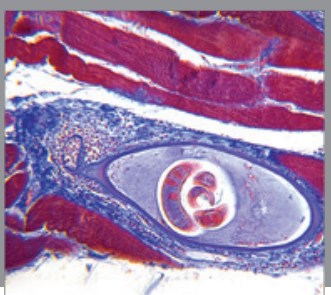

Gastroenterology

Research and Practice
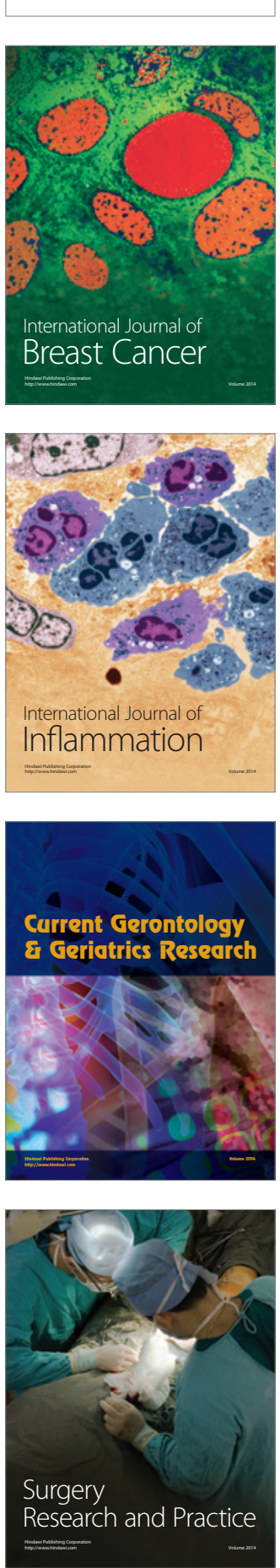

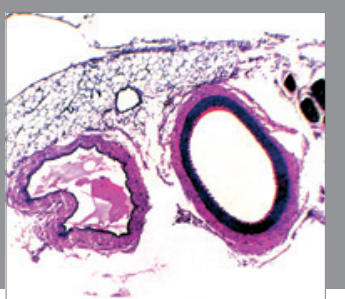

International Journal of Hypertension
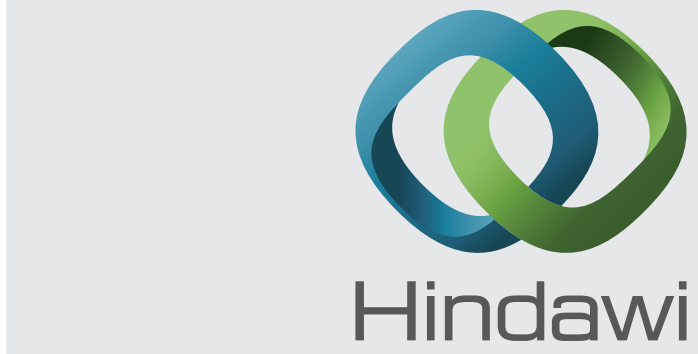

Submit your manuscripts at http://www.hindawi.com
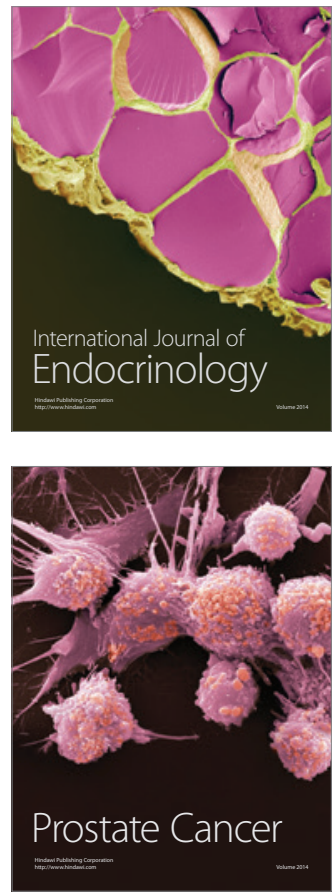

The Scientific World Journal
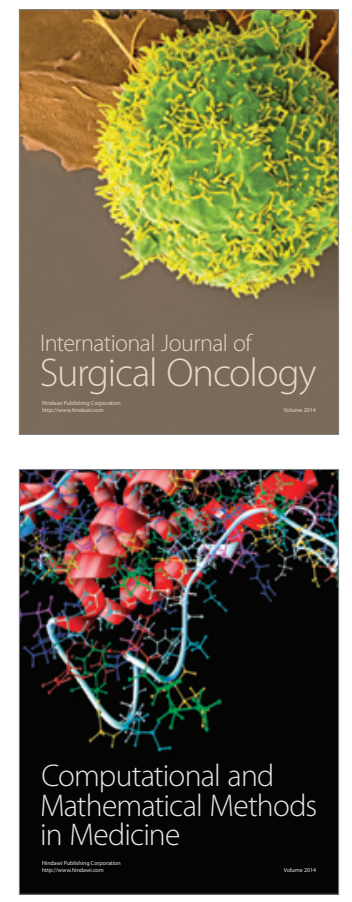
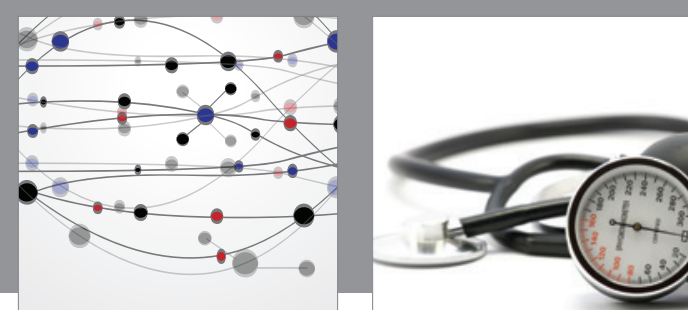

Nursing

Research and Practice

Research and Practice
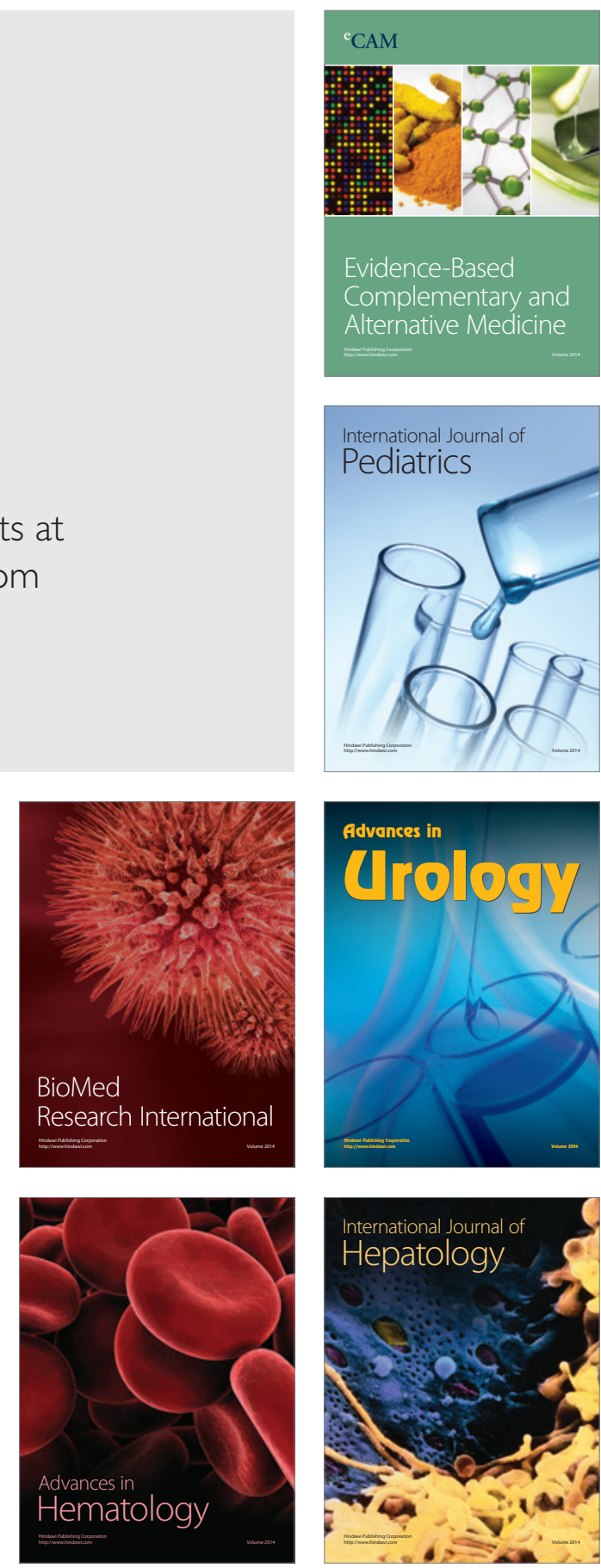
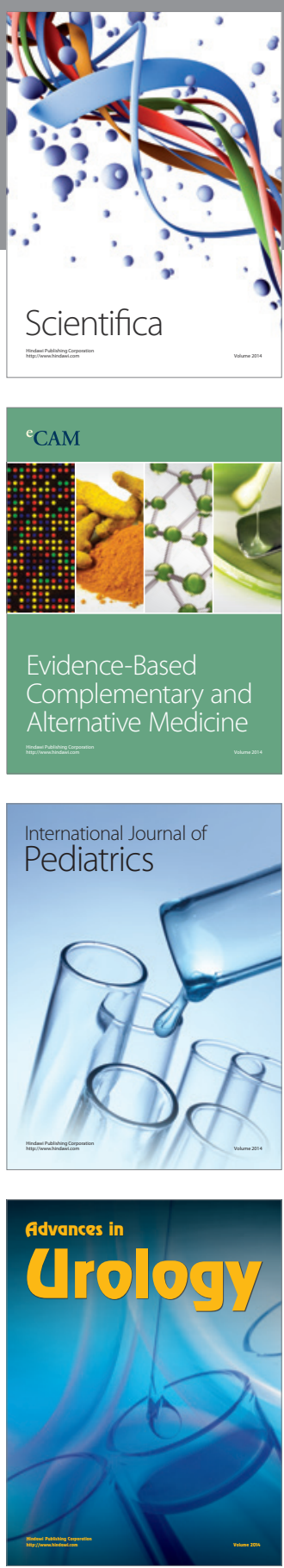

Scientifica

Evidence-Based

Complementary and

Alternative Medicine

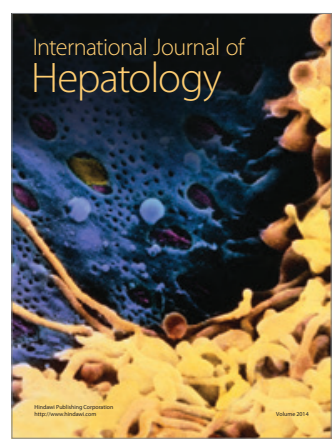

